\title{
A Study of the Optimal Deployment of Tsunami Observation Instruments in Korea
}

\author{
Eunju Lee $\circledast^{*}$, Taehwa Jung $\circledast^{* *}$, Ji-Chang Kim $\circledast^{*}$ and Sungwon Shin $\circledast^{*}$ \\ "Marine Science and Convergence Engineering, Hanyang University, Ansan, Korea \\ ${ }^{* *}$ Hanbat University, Deajeon, Korea
}

\section{지진해일 조기탐지를 위한 한국의 지진해일 관측장비 최적 위치 제안 연구 \\ 이은주@* 정태화@* · 김지창@* · 신성원@* \\ "한양대학교 해양융합과학과 \\ "한밭대학교 건설환경교통학부}

KEY WORDS: Tsunami 지진해일, Early Detection System 조기탐지 시스템, Offshore observation Instruments 외해 관측 장비, Optimal deployment 최적 배치, Tsunami propagation model 지진해일 전파 수치모델

\begin{abstract}
It has been an issue among researchers that the tsunamis that occurred on the west coast of Japan in 1983 and 1993 damaged the coastal cities on the east coast of Korea. In order to predict and reduce the damage to the Korean Peninsula effectively, it is necessary to install offshore tsunami observation instruments as part of the system for the early detection of tsunamis. The purpose of this study is to recommend the optimal deployment of tsunami observation instruments in terms of the higher probability of tsunami detection with the minimum equipment and the maximum evacuation and warning time according to the current situation in Korea. In order to propose the optimal location of the tsunami observation equipment, this study will analyze the tsunami propagation phenomena on the east sea by considering the potential tsunami scenario on the west coast of Japan through numerical modeling using the COrnell Multi-grid COupled Tsunami (COMCOT) model. Based on the results of the numerical model, this study suggested the optimal deployment of Korea's offshore tsunami observation instruments on the northeast side of Ulleung Island.
\end{abstract}

\section{1. 서 론}

지진해일은 인류에게 가장 큰 피해를 주는 자연현상 중 하나 이다(Pugh and Woodworth, 2014). 이를 뒷받침하는 사례는 지난 수십년간 발생한 지진해일 중 대표적으로 2011년 동일본 대지 진(규모 9.0)이 있고, 이 지진은 관측역사 상 4 번째로 큰 규모로, 이 지진에 의해 발생한 지진해일의 피해까지 가중되어 일본에 인명 피해(사망 15,894 명, 부상 6,152 명, 실종 2,562명) 그리고 재산 피해가 발생하였다(일본 경찰청 2016년 3월 발표 기준). 또한, 2011년 동일본 대지진으로 인한 범람 피해가 없을 것이라 고 예측했던 지역마저 피해가 발생하였다(Mori et al., 2018). 따 라서, 이러한 파괴적인 지진해일의 피해를 대비하기 위해 해외 에서는 진앙으로부터 거리 등 지형 특성에 맞게 지진해일 경보 시스템을 구축하여 왔다(Kim, 2008). 대표적인 예로 대양의 해 저 지진대에서 발생하고 전파되는 원거리 지진해일을 전 세계
에 위치한 부이를 이용하여 관측하고 연안에 경보하는 시스템 으로 미국에서 운용하는 Deep-ocean assessment and reporting of tsunamis(DART)가 있다(Fig. 1). 그리고 해안가 부근 해저 지진 대에서 발생하여 연안에 10 분 내외로 내습하는 근거리 지진해 일에 대비한 시스템이 일본과 캐나다에 수립되었다. 일본의 경 우, 150 개의 해저 지진계와 수압계로 이루어진 해저 관측 시스 템들이 일본 동쪽에 위치한 해구를 따라 총 $5,800 \mathrm{~km}$ 길이의 광 케이블로 연결되어 24 시간 지진대에서 발생하는 지진과 지진해 일을 감시하는 시스템인 S-net을 구축하고 있다(Kanazawa, 2013). 일본의 또 다른 해저 케이블시스템으로 Dense oceanfloor network system for earthquakes and tsunamis(DONET)는 난카이 트러프 (Nankai Trough)에서 발생가능한 지진과 지진해일을 감시하고 있다(Kaneda et al., 2015). 또한 해저케이블 시스템 이외에 일본 연안에서 $10-20 \mathrm{~km}$ 떨어진 지진해일을 감시하고 있다(Kaneda et al., 2015). 또한 해저케이블 시스템 이외에 일본 연안에서 $10-20 \mathrm{~km}$

Received 13 November 2019, revised 25 November 2019, accepted 19 December 2019

Corresponding author Sungwon, Shin: +82-31-400-5533, sungwshin@hanyang.ac.kr ORCID: http://orcid.org/0000-0002-4564-2627 It is noted that this paper is revised edition based on proceedings of KSOE 2019 in Gimhae.

(C) 2019, The Korean Society of Ocean Engineers

This is an open access article distributed under the terms of the creative commons attribution non-commercial license (http://creativecommons.org/licenses/by-nc/3.0) which permits unrestricted non-commercial use, distribution, and reproduction in any medium, provided the original work is properly cited. 

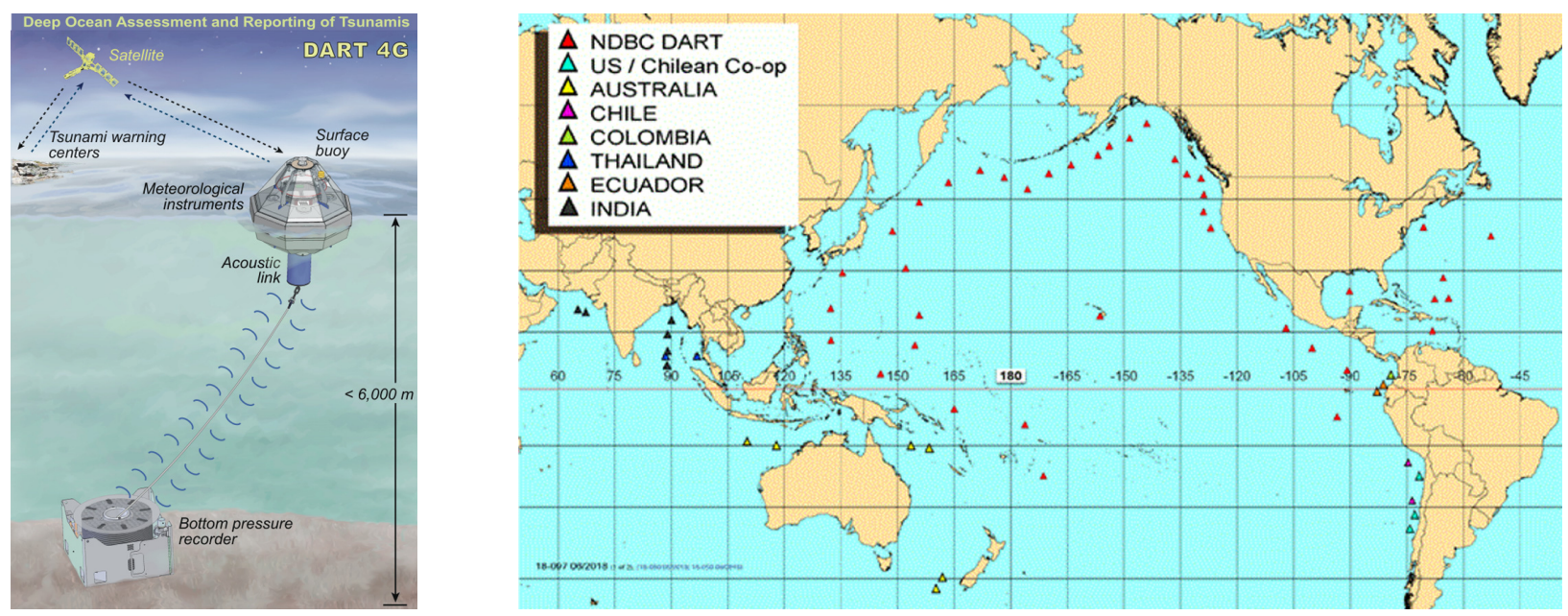

Fig. 1 DART system (left: the mooring of DART, right: the deployed DART location map) (NOAA, n.d.)

떨어진 수심 100-400m인 지역에 GPS(Global positioning system) 부이를 설치하여 2011년 동일본 지진해일을 관측하였다(Kawai et al., 2013). 일본과 비슷한 시스템으로 캐나다에 North-East Pacific time-series undersea networked experiment system인 해저 케이블 시스템도 구축되었다(Barnes et al., 2008).

우리나라에 피해를 주었던 1983년 동해중부 지진, 1993년 북 해도남서외해 지진이 발생한 일본 서해안에 위치하고 있는 지 진대에서 지진해일이 발생할 위험에 대해 연구자들이 우려하고 있다. 그 중 일본 서해안의 니가타 해역, 돗토리 해역 그리고 오 키나와 해역의 류쿠 해구가 일본의 지진공백역으로 대두되고 있다(Okinawa Prefecture Civil Engineering Department, 2015; Japan Society of Civil Engineers, 2016)(Fig. 2). 이에 한국 기상청 은 기존의 지진해일 관측 장비 활용을 우선으로 하여 지진해일 탐지 기술을 개발하여 왔다. 기존 지진해일 관측 장비는 울릉도 연안에 위치한 울릉도 극초단파식 해일파고계와 한반도 연안에 위치한 연안방재 관측 장비 그리고 국립해양조사원에서 운영하 는 조위관측소가 있다. 세 지진해일 관측 장비는 장주기 파랑 측정 장비로 지진해일과 같은 파장이 긴 파랑을 측정할 수 있

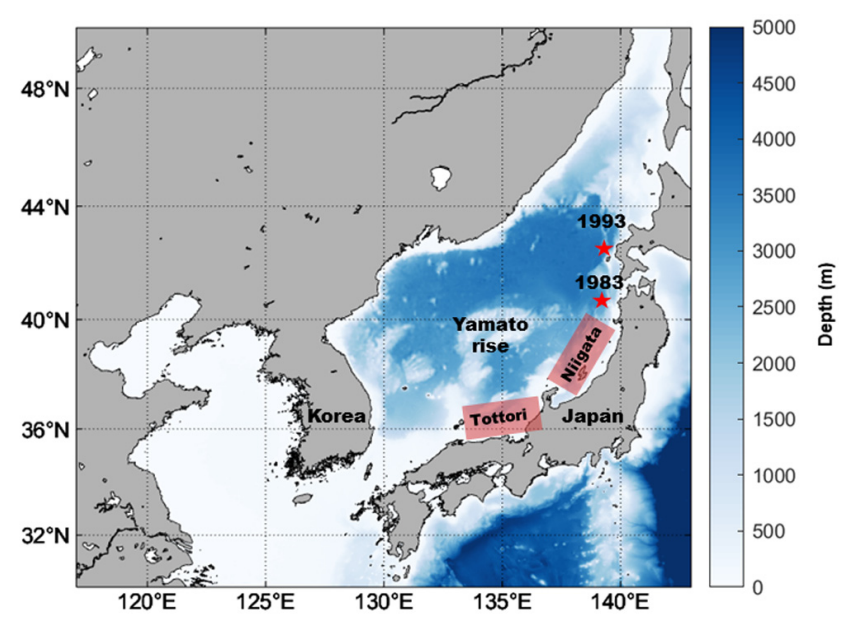

Fig. 2 Computational domain of COMCOT and the location of earthquake occurred in 1983 and 1993 (red stars) and potential earthquake zone (red boxes)
다. 그러나, 우리나라의 모든 지진해일 관측 장비는 연안에 위 치하고 있기에, 울릉도를 포함한 한반도 연안 지역에 대한 지진 해일 조기 경보 기능을 수행하기 어렵다. 따라서, 기상청은 연 안에 도달한 지진해일은 천수효과와 만 내의 공진현상 등으로 인해 발생한 지진해일 파원의 성분을 잃어버려 이론적으로 알 려진 지진해일 성분을 주파수에 따라 분류하기 복잡하며 또한 지진해일 파원 추정 시 한계를 지닌다(Titov et al., 2005; Levin and Nosov, 2009). 관측 자료를 활용한 지진해일 파원 추정 기술 의 정확도는 연안에 도달하는 지진해일의 피해 추정의 정확도 에 기여한다(Gusman and Tanioka, 2014; Cienfuegos et al., 2018). 따라서, 지진해일 조기 탐지 목적과 향후 연안의 지진해일 피해 추정 정확도를 위해 본 연구는 현재 한국의 지진해일 예경보 시스템을 고려하여 미국의 DART와 일본의 해저케이블 시스템 과 같은 외해 지진해일 관측 장비의 최적 위치를 제안하고자 한다.

이에 더하여, 지진해일 관측 장비의 위치 선정은 기술적 및 경제적 상황도 고려해야 한다(Araki et al., 2008). 또한 어업권과 같은 법적인 요소도 무시할 수 없다(Abe and Imamura, 2013). 이 러한 사항들을 고려함과 동시에 지진해일 경보 시스템의 목적 에 부합한 지진해일 관측 장비의 최적 배치 지역을 제안한 연 구도 있다(Omira et al., 2009; Schindele et al., 2008).

따라서 본 연구는 위의 선행 연구들을 바탕으로 다음과 같은 한국의 현황을 고려하여 지진해일 관측 장비 배치 최적 지역을 제안하고자 한다. 먼저, 한국 동해안에 형성된 대화퇴는 지진해 일 전파에 큰 영향을 미친다(Cho and Lee, 2013). 그 예로 1931 년, 1993년 지진 당시 한반도 동해연안의 특정 지역에서만 지진 해일의 피해가 발생하였다(Jeon et al., 2007). 따라서 본 연구는 다양한 조건의 가상 지진 시나리오를 선행연구로부터 선정하고 COMCOT(Cornell multi-grid coupled tsunami model)을 활용하여 한국 동해안 해저 지형에 따라 지진해일이 전파되는 특성을 연 구하고 지진해일 관측 장비 위치 선정에 고려하고자 한다. 또한 $\mathrm{Okal}(2015)$ 에 의하면, 연안 지역의 인명피해와 재산손실을 줄이 는 가장 효율적인 방법은 조기에 지진해일을 관측하여 대피 시 간을 최대한 확보하는 것이라고 명시하였다. 더불어, 지진해일 관측 장비 설치 및 유지 보수비용에 대한 경제적 조건도 무시 
할 수 없다. 따라서, 본 연구는 최소한의 장비로 한국 동해의 지 형을 고려하여 지진해일이 주로 지나가는 지역을 고려하여 지 진해일의 탐지 확률을 높이고, 사전 경보 시간을 최대한 확보하 여 연안의 피해를 최소한으로 줄이는 것에 목적을 두고 외해 지진해일 관측 장비의 최적 위치를 제안하고자 한다.

\section{2. 지진해일 전파 예측을 위한 수치모형 실험}

선행연구(Choi et al., 2001; Kim et al., 2013; Kim and Cho, 2014; Rehman and Cho, 2016; Jho et al., 2019)에서 사용한 다양 한 조건의 가상 지진 시나리오를 선정하고 $\mathrm{COMCOT}$ 을 이용하 여 일본 서해안에서 발생하는 지진해일이 동해안의 지형에 의 해 생기는 지진해일의 전파 특성을 분석함으로써, 한반도 동해 외해 지진해일 관측 장비의 최적 위치 연구를 진행하였다. COMCOT은 선형 및 비선형 천수방정식을 지배방정식으로 사 용하고 이를 유한차분법을 통하여 푼다. 이 수치모델을 통하여 많은 지진해일의 발생부터 전파 그리고 침수까지의 연구가 이 루어졌다(Wu et al., 2008; Lee et al., 2015; Mueller et al., 2015). COMCOT은 Yoon(2002)이 제안한 방법을 통하여 분산효과를 고 려하고, 특히 전지구 지진해일 전파 모델에서 필수적으로 고려 해야 할 전향력과 구면좌표계를 지원한다(Wang, 2008).

\section{1 가상 지진 시나리오}

지진해일 관측 장비 위치 선정 시, 지진과 지진해일이 일어날 가능성이 높은 곳의 시나리오를 사용하는 것은 필수 조건이다 (Mulia et al., 2017). 따라서, 본 연구는 한국 동해안에 영향을 미 칠 수 있는 일본 서해안에서 발생한 가상 지진해일 시나리오를 고려하였고, 여러 선행 연구를 통해 다양한 조건의 가상 지진 시나리오 40개를 선정하였다(Choi et al., 2001; Kim et al., 2013;
Kim and Cho, 2014; Rehman and Cho, 2016; Jho et al., 2019). 대 표적인 지진해일 시나리오 3 개의 케이스를 그림에 명시하였다 (Fig. 3).

\section{2 수치모델 입력 조건}

$\mathrm{COMCOT}$ 을 수행한 동해안의 계산 영역은 Fig. 2과 같으며, $116.9-142.9^{\circ} \mathrm{E}, 29.9-49.9^{\circ} \mathrm{N}$ 의 지역이다. 실제 수심자료인 15 arc second로 구성된 The general bathymetric chart of the oceans (GEBCO)를 30 arc second로 리샘플링하여 사용하였다. 또한 COMCOT의 시뮬레이션 시간은 4시간이며, 시간 간격은 1 초 간 격으로 진행하였다. 또한 외해에 설치될 지진해일 관측 장비를 고려하여 선형 천수방정식을 사용하여 수치모델을 수행하였다.

\section{3. 외해 지진해일 관측 장비 설치 최적 지역 제안}

\section{1 동해안 지진해일 전파 특성 분석}

본 연구에서 외해 지진해일 관측 장비는 자유수면 변위를 기 록하고, 지진해일을 탐지할 수 있는 시공간적인 사양을 가진다 는 것을 전제로 한다. 지진해일 관측 장비는 지진해일 에너지가 많이 분포하는 곳에 위치해야 한다(Mulia et al., 2017). 따라서, Mulia et al.(2017)은 수치모델을 통하여 얻은 지진해일 전파도를 Empirical orthogonal function(EOF) spatial mode를 통하여 특정 지진해일 시나리오들의 에너지가 주로 분포하는 곳을 찾아 지 진해일 관측 장비의 최적 위치로 제안하였다. 하지만, 이 선행 연구의 경우, 한국의 현황과 달리 넓은 범위의 지진해일 파원을 다루지 않고, 큰 규모의 특정 시나리오 11 개에서 지진해일 파원 추정 정확도를 기준으로 지진해일 관측 장비의 최적 배치 지역 을 제안하였다. 또한, 최근 외해 지진해일 관측 장비 제안 연구 의 경우, 지진해일 파원 추정의 정확도를 기준으로 지진해일 관
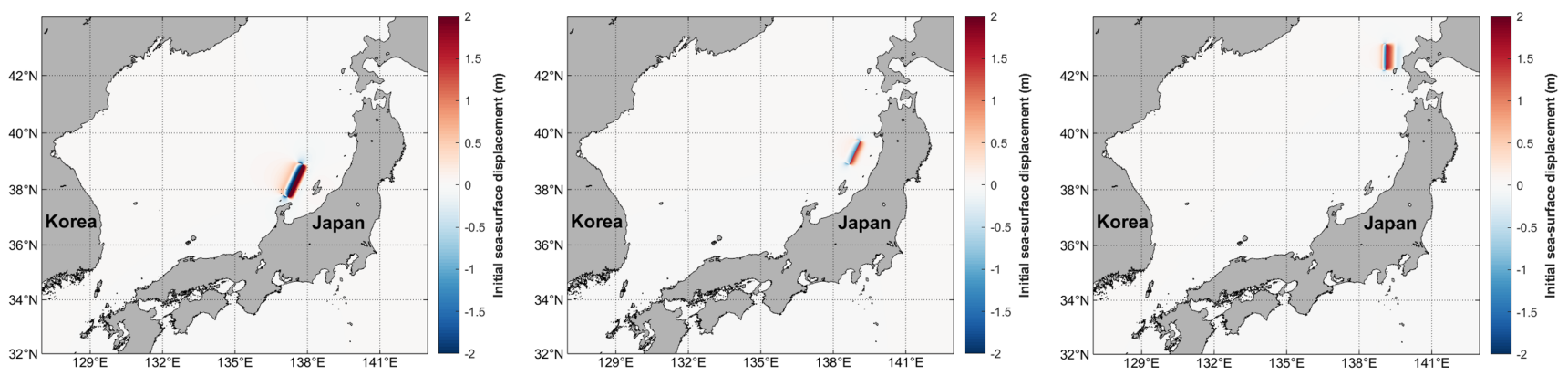

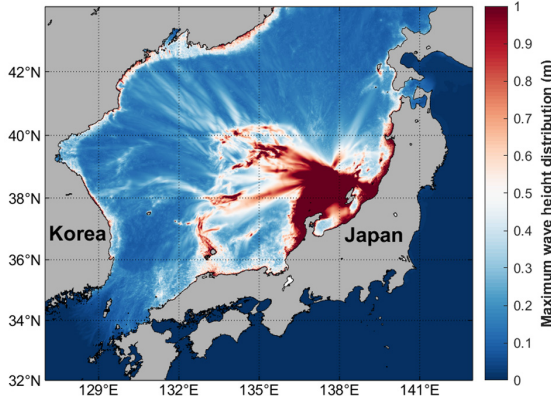

(a) Case 04

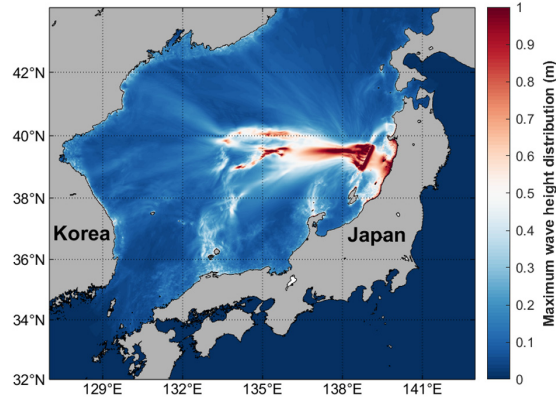

(b) Case 10

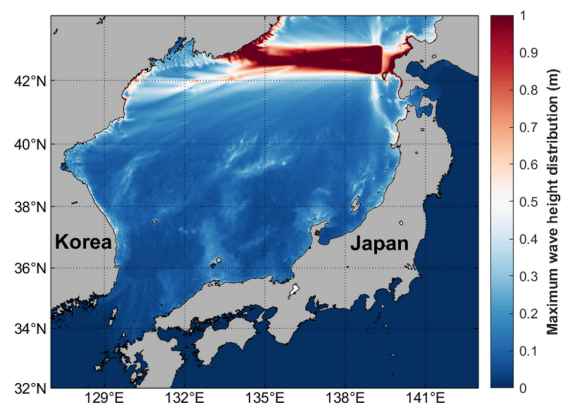

(c) Case 30

Fig. 3 Examples of potential tsunami scenarios (top: initial sea-surface displacement of each scenario, bottom: maximum wave height distribution of each scenario) 
측 장비 최적 위치를 제안하였다(Mulia et al., 2017; Meza et al., 2018). 그러나 현재 충분한 양의 장비가 보유되지 않은 한국의 지진해일 경보 시스템 현황을 고려하여, 최적 관측 지역 선정의 기준을 파원 추정의 정확도를 기준으로 고려하는 것이 아니라, 한국 동해 지형의 특성을 이용하여 지진해일 탐지 확률을 높이 는 지역을 제안하고자 한다. 따라서 본 연구의 전제는 지진해일 관측 장비는 지진해일 에너지가 많이 분포하는 곳에 위치해야 하고, 지형의 영향을 받지 않아 지진해일의 성분이 왜곡되지 않 으며 동시에 지진해일이 심해에서 속도가 빠른 점을 고려하여 수심 $300 \mathrm{~m}$ 보다 깊은 곳으로 제안하였다(Schindele et al., 2008; Mulia et al., 2017).

Mulia et al.(2017)과 Omira et al.(2009)의 연구 방법론을 착안 하여 $\mathrm{COMCOT}$ 으로부터 나온 지진해일 최대파고분포도를 분석 함으로써 다양한 조건의 수많은 가상 지진해일이 우리나라 동 해에 전파되는 특성을 분석하였다.

우리나라 동해를 전파하는 지진해일은 동해 중부에 형성된 대화퇴(야마토 라이즈)를 포함한 수중산맥의 영향으로 일본 서 해안에서 발생하는 지진해일의 피해는 주로 동해 연안 특정 지 역에 영향을 주고 있다(Jeon et al., 2007). 따라서 다양한 조건의 수많은 지진해일 시나리오의 최대파고분포도를 통하여 특정 지 역에서 지진해일이 전파가 되는 것을 확인할 수 있었다. Meza et al.(2018)에서 지진해일의 에너지가 지나감으로써 지진해일이 관측되는 지역을 listening area로 정의하고, 두 지진해일 시나리 오의 최대파고분포도를 겹침으로써, 지진해일 관측 장비의 최 적 위치를 제안하였다. 따라서 본 연구도 선행연구(Meza et al., 2018)의 방법을 착안하여 다양한 조건의 가상 지진해일 시나리 오의 최대파고분포도가 가장 많이 겹치는 곳에 외해 지진해일 관측 장비 최적 배치 지역으로 제안하였다.

한국 국립재난안전연구원은 한반도 주변해역에서 규모 7.0 이 상의 해저지진으로 인해 발생한 지진해일이 연안에 도달하였을 때의 파고가 $0.5 \mathrm{~m}$ 이상 $1 \mathrm{~m}$ 미만일 시 지진해일 주의보를 내린
다. 따라서, 본 연구는 연안 해저 지형의 영향으로 인해 지진해 일의 파고가 높아지는 것을 감안하여, 모든 시나리오를 이용하 여 각 격자점에 대해 $0.1 \mathrm{~m}, 0.2 \mathrm{~m}, 0.3 \mathrm{~m}$ 이상의 지진해일 파고가 지나간 빈도에 대한 확률을 Maximum likelihood estimation을 이 용하여 계산하였다. Maximum likelihood estimation은 패턴 분석 에 관한 기본적인 통계 기법으로 미지의 $P$ 인 확률분포에서 뽑 은 표본(관측치) $x$ 를 바탕으로 $P$ 를 추정하는 것이다. 따라서, 외해 지진해일 관측 장비 설치 최적 지역을 Fig. 4의 삼각형 내 지역으로 제한하였다.

\section{2 사전 경보 시간 확보}

최소한의 장비 수로 지진해일 탐지 확률을 높이기 위하여, 우 선 다양한 조건하에서 많은 가상 지진해일 시나리오를 통해 지 진해일이 가장 많이 지나가는 영역, 즉, 탐지 확률이 높은 영역 을 선정한 후 Schindele et al.(2008)에 따라 그 지역 내 관측 장 비에 지진해일 도달시간이 최소인 지역을 선택하여 사전 경보 시간 확보 최대화 기준으로 최적 관측 지역을 선정 및 제안하 였다. 경보 시간에 대한 기준은 Schindele et al.(2008)과 Omira et al.(2009)에서 제안한 방법을 사용하였다. 사전 경보 시간 최대 확보를 위한 필수 고려 요소는 지진해일 탐지 후 경보센터에 관측자료 전송 및 지진해일 확인 및 경보 소요 시간이다.

$$
W T=T T T-(D d+D t+D c)
$$

식 (1)의 Warning time(WT)은 해당 연안 지역에 지진해일을 경 보함으로써 확보하는 대피 가능 시간을 의미하고, Tsunami travel $\operatorname{time}(T T T)$ 는 지진해일 발생원으로부터 해당 정점까지 지진해일 초기 파형 도달 시간이다(IOC 2006 Tsunami Glossary). 이는 지진 해일 경보 시스템에서 고려되는 필수 요소이다(Schindele et al., 2008). Delay of detection $(D d)$, Delay of transmission $(D t)$, Delay of confirmation $(D c)$ 은 지진해일 관측 장비에서 지진해일 초기 파형
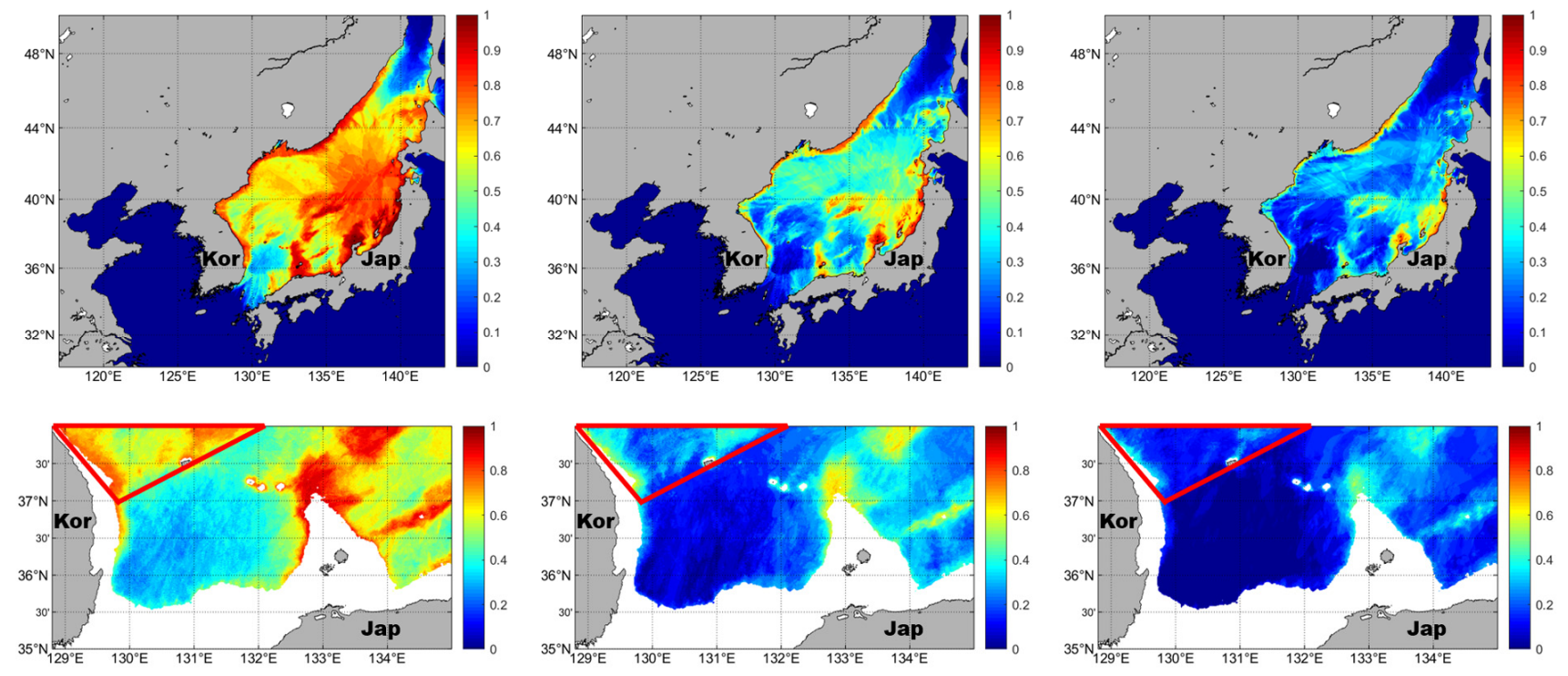

Fig. 4 The result of maximum likelihood estimation of maximum wave height distribution from 40 potential tsunami scenarios (left: standard $0.1 \mathrm{~m}$, middle: standard $0.2 \mathrm{~m}$, right: standard $0.3 \mathrm{~m}$ ). The red triangle means optimal location of tsunami instrument regarding to tsunami detection efficiency. 
의 진폭 및 지진해일을 정의하는 기준점까지의 탐지 소요 시간, 지진해일 관측 장비로부터 지진해일 경보센터에로 관측자료 전 송 소요시간, 지진해일 경보센터에서 경보 전 지진해일 확인 소 요 시간을 각각 의미한다. $D d$ 의 경우, 지진해일 초기파형 주기는 평균 20분이다. 따라서, 지진해일 초기파형의 진폭을 탐지하기 위해서 대략 6-8분이 소요된다. 따라서 $\mathrm{Dd}$ 는 선행연구에 의거하 여 8 분으로 정의한다. 또한, 사전 경보시간 최대 확보를 위해 가 장 짧은 시간이 소요되는 전송방식을 고려하여, 근거리 지진해 일에 대해 해외에서 주로 사용하는 외해 지진해일 관측 장비의 통신 방법인 Inmarsat satellites를 이용한 Broadband global area network를 사용한다고 가정하였을 때, 자료 전송시간은 2 분이 소 요된다(Schindele et al., 2008). 따라서, 지진해일 초기파형 진폭을 관측 후 자료 전송까지 10 분이 소요된다 $(D d+D t)$. 또한 지진해
일 경보센터에서 지진해일 확인을 위해 최소 지진해일 초기파형 파장의 $1 / 4$ 길이의 자료가 필요하다. 따라서, $D c$ 는 선행연구와 동일하게 5 분이라고 가정한다(Omira et al., 2009). $D d, D t, D c$ 는 최대 15 분임이 정해진다. 따라서, 지진해일 관측 장비로부터 지 진해일을 관측 및 자료전송 그리고 지진해일 경보센터에서의 지 진해일 확인 및 경보 시간 15 분과 대피 시간 최소 15 분을 고려하 여 연안으로부터 지진해일이 도달하기 30 분 전에 지진해일을 탐 지하는 장비 위치를 지진해일 조기탐지를 위한 최적 위치로 제 안하였다. 선행연구들에서 가상 외해 지진해일 관측 장비를 설 치할 때 자료의 중복성을 피하기 위하여 $30 \mathrm{~km}$ 간격을 고려한다 (Mulia et al., 2017). 하지만, 우리나라의 경우 설치 및 유지비용 을 고려하였을 때, 외해 지진해일 관측 장비를 해저 케이블과 같 이 배열 형태로 설치할 것이 아닌, 장비 수를 최소화할 것이기

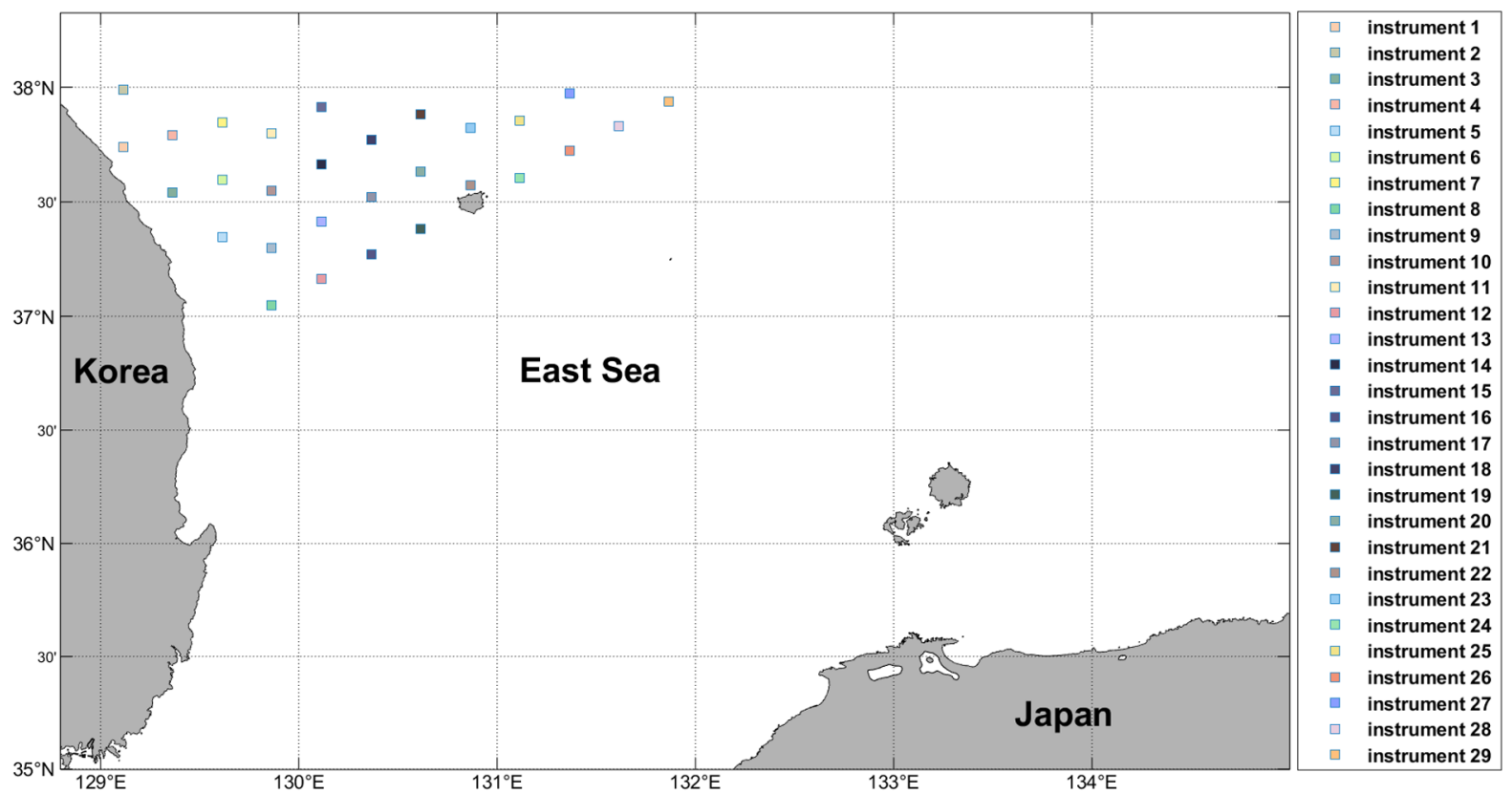

Fig. 5 Possible instrument locations for tsunami detection based on Fig. 4.

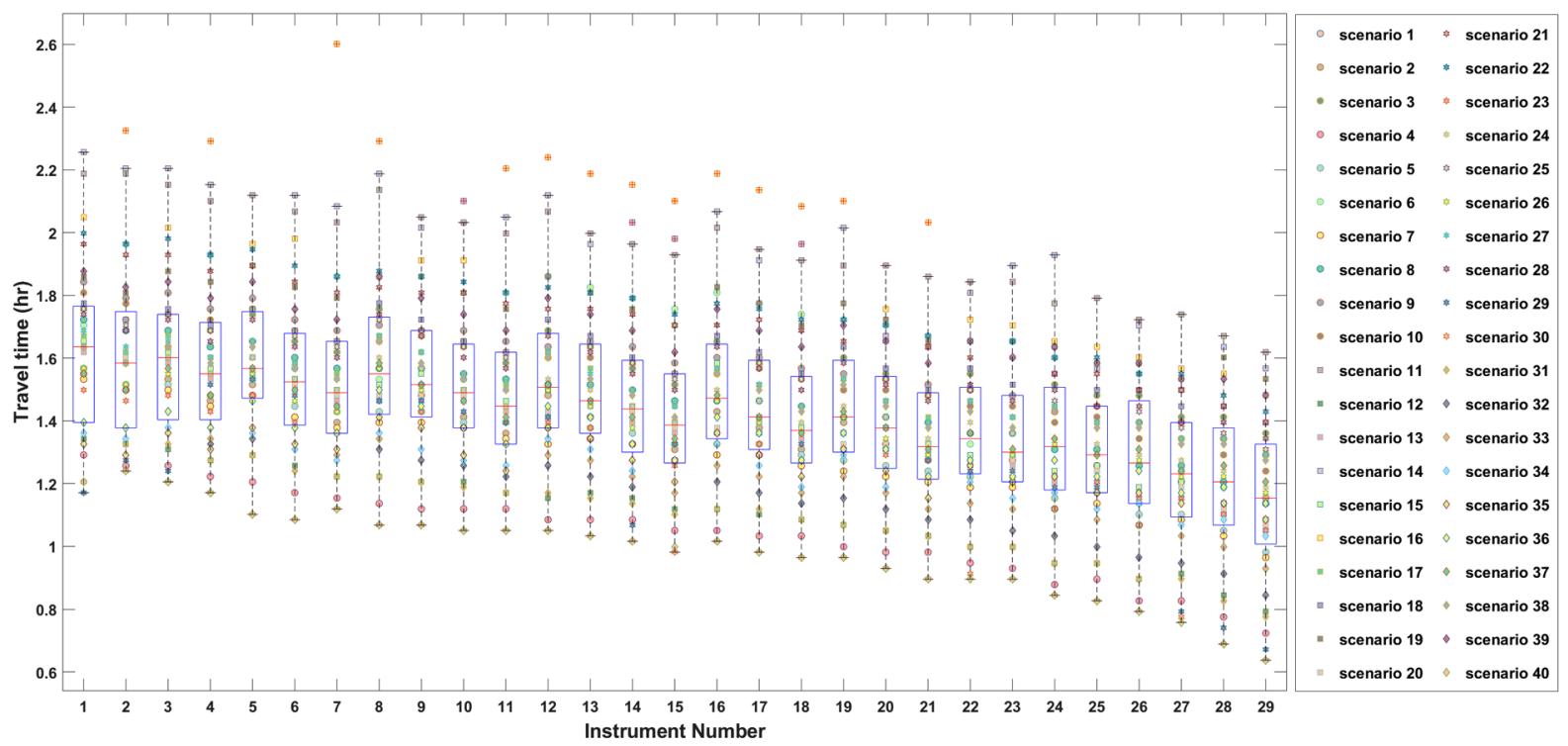

Fig. 6 Tsunami travel time on the virtual instruments for the 40 scenarios 


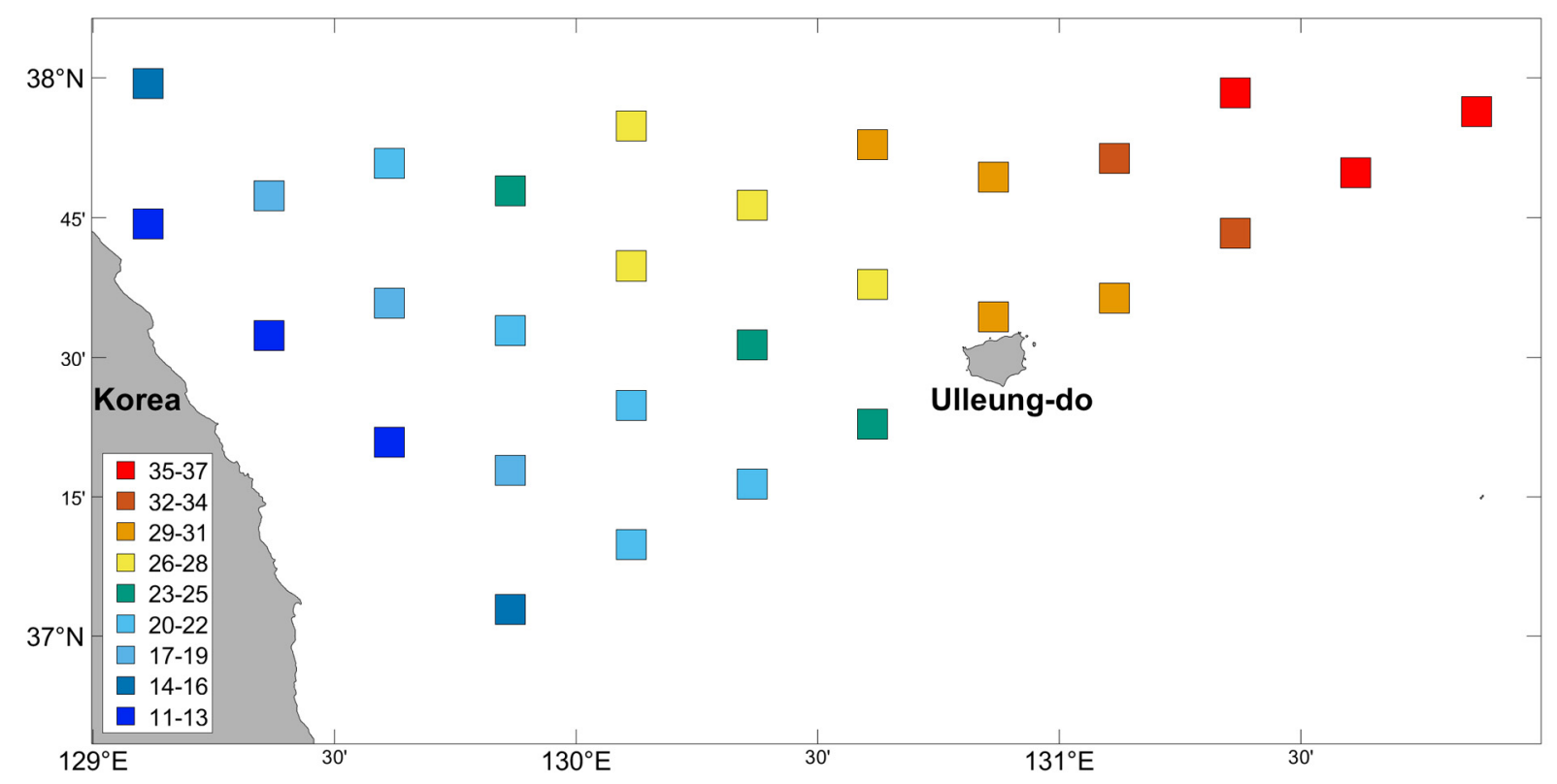

Fig. 7 The number of scenario that the tsunami travel time is less than 1.5 hours

때문에 $30 \mathrm{~km}$ 보다 적은 $25 \mathrm{~km}$ 간격으로 가상 지진해일 관측 장비 를 제한된 구역(Fig. 4의 빨간색 삼각형으로 표시) 내에 설치하였 다(Fig. 5). 지진해일 발생원으로부터 가상 관측 장비까지의 지진 해일 도달시간을 COMCOT을 이용하여 계산하였다. 실제 1983 년, 1993년 일본 서해안에서 지진해일이 발생하여 한반도 동해 안까지의 전파시간이 2시간인 점을 고려하여(Kim, 2008), 외해 지진해일 관측 장비에 지진 발생 직후 최소 1 시간 30 분 전에 지 진해일 관측 및 탐지가 이루어져야 한다. 따라서, 모든 시나리오 에 대한 각 장비의 지진해일 도달시간을 4 분위수로 표현하고 (Fig. 6), 가상 지진해일 관측 장비 별 1 시간 30 분 전에 관측된 시 나리오 수를 확인함으로써 최적 장비 배치 지역을 선정하였다 (Fig. 7). 따라서, 지진해일 발생 직후 1 시간 30 분 전에 지진해일 탐지 빈도수가 가장 높은 가상 지진해일 관측 장비의 위치인 울 릉도 북동쪽을 최적 지역으로 제안하는 바이다(Fig. 7의 빨간색, 지진해일 탐지 빈도 수 35-37)

\section{3 장비 설치를 위한 추가적 환경 고려 사항}

마지막으로 설치 가능한 지역인지 고려하여야 한다. 이는 외 해 지진해일 관측 장비가 설치 가능 조건인지 고려가 필요하다. 부이식 장비 또는 해저 케이블을 설치하기 위해서는 물리적인 지형조건으로는 해저면의 경사가 비교적 완만한 곳이어야 한다. Omira et al.(2009)은 Geographic Information System technology를 이용하여 해저 경사도를 계산하고 경사 3 도 이하 지역을 장비 설치 가능 지역 경사 기준으로 정의하였다. 따라서, 본 연구는 선행연구의 기준을 사용하여 경사 3 도 이상으로 설치 불가능 지역의 경사를 빨간색으로, 경사 3 도 이하 설치 가능 지역의 수 심을 파란색으로 표시하였고, 제안된 지진해일 관측 장비 위치 와 현재 설치된 기상청의 해양기상부이, 울릉도 해일파고계, 국 립해양조사원의 해양관측부이 그리고 1983년 지진해일 피해를 입었던 임원항의 위치를 나타내었다(Fig. 8). 상기 모든 고려사 항을 조합하여 Fig. 8에서 노란색으로 표기된 세 위치가 지진해

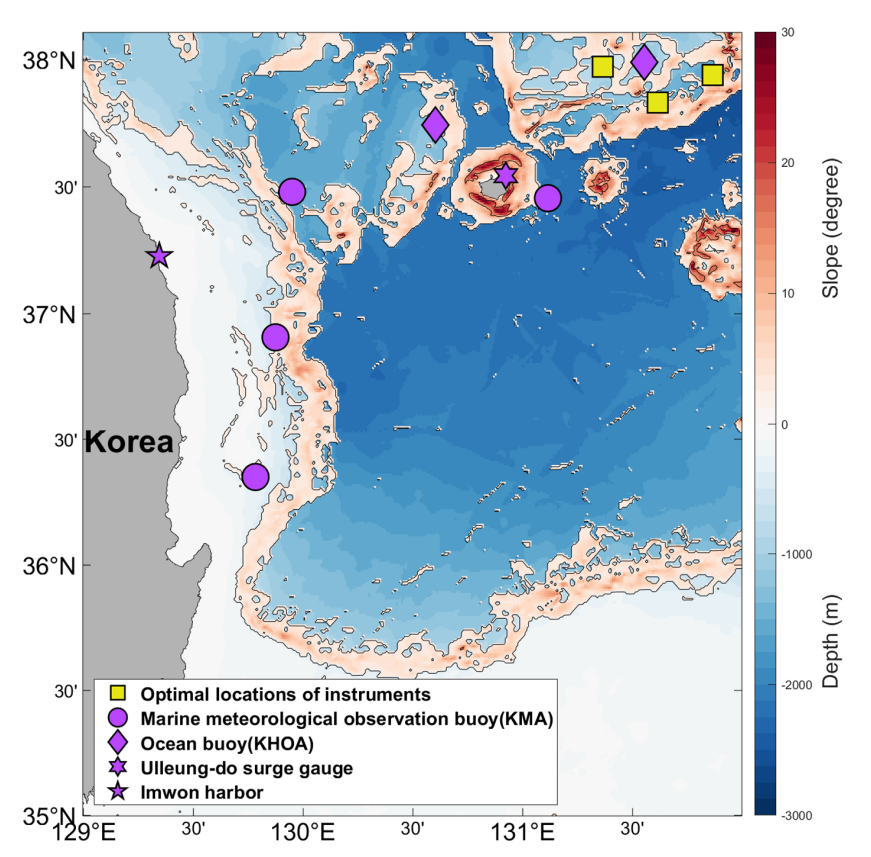

Fig. 8 The bottom slope and bathymetry map of the East sea and the optimal (green) and existing (purple) locations of instruments including wave buoys of Korea Meteorological Administration and Korea Hydrographic and Oceanographic Agency(stars and diamonds) and tidal gages of Imwon harbor (stars).

일의 조기 탐지를 위하여 바람직한 위치라는 결과를 도출하게 되었다.

\section{4. 결 론}

본 연구에서는 국내의 제한적 상황(원거리에 위치한 지진해 일 진원지, 부족한 장비 등)에서 동해안의 해안 도시 재해 저감 
을 목표로 하는 지진해일 관측 장비 위치를 제안하고자 하였다. 이를 위하여 기존에 존재하는 지진해일 시나리오를 바탕으로 $\mathrm{COMCOT}$ 을 활용하여 지진해일 전파 양상을 예측하고, 각 격자 별 지진해일 전파 빈도, 도달시간, 수심, 해저 경사를 고려하여 최적 관측 장비 설치 지점을 파악하였다.

본 연구의 목적은 최소한의 장비로 지진해일 탐지 확률을 높 이고, 사전 경보시간을 최대한 확보함으로써 지진해일의 피해 를 줄이기 위함이다. 더 나아가, 지진해일 관측 장비 배치 지역 을 지진해일이 주로 지나가는 지역에 배치함으로써 향 후 지진 해일 파원 추정에 지진해일 관측 자료를 통하여 지진해일 피해 의 예측 정확도를 높이는데 기여하고자 한다. 따라서, 본 연구 는 선행 연구들을 참고하고, 본 연구의 접근 방법을 토대로 Fig. 8 에서 도시한 바와 같이 울릉도 북동쪽 지역을 지진해일 관측 장비 최적 배치 지역으로 제안하였다.

또한 울릉도 북동쪽에 외해 지진해일 관측 장비 설치 및 운용 시, 현재 기상청 지진해일 관측 장비 중 최우선순위인 울릉도 해일파고계와 연동함으로써 향 후 지진해일이 연안에 들어오면 서 천수효과 등에 의해 영향을 받은 지진해일 특성을 연구할 수 있으며, 울릉도 도달하기 전 울릉도 지진해일 경보를 시행할 수 있다.

그리고 향 후 파원 추정 연구도 고려하였을 때, 지진해일의 주 에너지가 지나가는 지역에 지진해일 관측 장비가 2-4개 있어 도 충분하다는 Percival et al.(2011)에 의거하여 울릉도 북동쪽의 3 개의 위치를 제안하였다(Fig. 8).

본 연구가 제안한 최적 위치에 지진해일 관측장비가 해저케 이블로 구성되거나, DART와 동일한 계류 방식으로 Fig. 8의 위 치에 설치된다면, 조기탐지 뿐만 아니라 향 후 정량적인 지진해 일 파원 추정을 통해 연안 지역의 피해 예측 정확도 향상에도 기여할 수 있다.

본 연구는 향 후 40 개의 시나리오를 포함한 더 많은 수의 시 나리오 그리고 경제성까지 고려하여 지진해일 관측 장비 최적 배치 지역을 연구할 예정이며, 동일한 연구 방법으로 남해안에 도 적용할 계획이다.

\section{후 기}

본 연구는 한국기상산업기술원(KMI2018-02510)과 한국연구재 단 기초연구지원사업(NRF-2017R1A2B4010108)의 지원으로 수 행된 연구결과이며, 연구비 지원에 감사드립니다.

\section{References}

Abe, I., Imamura, F., 2013. Problems and Effects of a Tsunami Inundation Forecast System During the 2011 Tohoku Earthquake. Journal of Japan Society of Civil Engineers, 1(1), 516-520. https://doi.org/10.2208/journalofjsce.1.1_516

Araki, E., Kawaguchi, K., Kaneko, S., Kaneda, Y., 2008. Design of Deep Ocean Submarine Cable Observation Network for Earthquakes and Tsunamis. Proceedings of OCEAN 2008-MTS/IEEE Kobe Techno=Ocean, Kobe Japan, 1-4. https://doi.org/10.1109/OCEANSKOBE.2008.4531071
Barnes, C.R., Best, M.M., Zielinski, A., 2008. The NEPTUNE Canada Regional Cabled Ocean Observatory. Technology (Crayford, England), 50.

Cho, Y.S., Lee, J.W., 2013. Hazard Map with Probable Maximum Tsunamis. Proceedings of the 23th International Offshore and Polar Engineering Conference, Alaska USA, 82-85.

Choi, B.H., Hong, S.J., Pelinovsky, E., 2001. Simulation of Prognostic Tsunami on the Korean Coast. Journal of Geophysical research Letters, 28(10), 2013-2016. https://doi.org/10.1029/ 2000GL012534

Cienfuegos, R., Catalán, P.A., Urrutia, A., Benavente, R., Aránguiz, R., González, G., 2018. What Can We Do to Forecast Tsunami Hazards in the Near Field Given Large Epistemic Uncertainty in Rapid Seismic Source Inversions?. Geophysical Research Letters, 45, 4944-4955. https://doi.org/10.1029/2018GL076998, 2018.

Gusman, A., Tanioka, Y., 2014. W Phase Inversion and Tsunami Inundation Modeling for Tsunami Early Warning: Case Study for the 2011 Tohoku Event. Pure and Applied Geophysics, 171, 1409-1422. 1409-1422. https://doi.org/10.1007/s00024$013-0680-\mathrm{z}$

Japan Society of Civil Engineers, 2016. Tsunami Assessment Technology for Nuclear Power Plants 2016. [Online] (Updated September 2016) Available at: <http://committees.jsce.or.jp/ ceofnp/system/files/NPP_TNMT_2016_main_20170814.pdf> [Accessed September 2019]

Jeon, Y.J., Lee, S.M., Lim, C.H., Yoon, S.B., 2007. Propagation Characteristics of 1983 Central East Sea Tsunami, Korean Society of Civil Engineers, 4572-4575.

Jho, M.H., Kim G.H., Yoon, S.B., 2019. Construction of Logic Trees and Hazard Curves for Probabilistic Tsunami Hazard Analysis. Journal of Korean Society of Coastal and Ocean Engineers, 31(2), 62-72. https://doi.org/10.9765/KSCOE.2019. 31.2.62

Kanazawa, T., 2013. Japan Trench Earthquake and Tsunami Monitoring Network of Cable-linked 150 Ocean Bottom Observatories and Its Impact to Earth Disaster Science. Journal of Underwater Technology Symposium (UT), 2013 IEEE International, 1-5. https://doi.org/10.1109/UT.2013.6519911

Kaneda, Y., Kawaguchi, K., Araki, E., Matsumoto, H., Nakamura, T., Kamiya, S., Ariyoshi, K., Hori, T., Baba, T., Takahashi, N., 2015. Development and Application of an Advanced Ocean Floor Network System for Megathrust Earthquakes and Tsunamis. Springer Praxis Books, 643-662. https://doi.org/ 10.1007/978-3-642-11374-1_25

Kawai, H., Satoh, M., Kawaguchi, K., Seki, K., 2013. Characteristics of the 2011 Tohoku Tsunami Waveform Acquired around Japan by NOWPHAS Equipment. Coastal Engineering Journal, 55(03), 1350008. https://doi.org/10.1142/ S0578563413500083

Kim, B.J., Cho, Y.S., 2014. Determination of Tsunami Height 
Distribution with L-moment Method.Journal of Korean Society of Hazard Mitigation, 14(1), 311-1317. https://doi.org/ 10.9798/KOSHAM.2014.14.1.311

Kim, H.S., 2008. Occurrence of Tsunami and Warning System. The Korean Society of Marine Engineering, 32(4), 490-497.

Kim, H.S., Kim, K.O., Jung, K.T., Lee, J.S., 2013. Development of Parallel Tsunami Programig Model(I). National Disaster Management Institute. Report No. NDMI-PR-2013-20-02.

Lee, J.H., Park, E.H., Park, S.C., Woo, S.B., 2015. Development of the Global Tsunami Prediction System Using the Finite Fault Model and the Cyclic Boundary Condition. Journal of Korean Society of Coastal and Ocean Engineers, 27(6), 391-405. https://doi.org/10.9765/KSCOE.2015.27.6.391

Levin, B., Nosov, M., 2009. Physics of Tsunami. Springer.

Meza, J., Catalán, P.A., Tsushima, H., 2018. A Methodology For Optimal Designing Of Monitoring Sensor Networks For Tsunami Inversion. Natural Hazards and Earth System Sciences, Under Review, Discussion started: 22 October 2018.

Mori, N., Goda, K., Cox, D., 2018. Recent Process in Probabilistic Tsunami Hazard Analysis (PTHA) for Mega Thrust Subduction Earthquakes. In the 2011 Japan Earthquake and Tsunami: Reconstruction and Restoration, 469-485. https://doi.org/10.1007/978-3-319-58691-5_27

Mueller C., Power W., Fraser S., Wang X., 2015. Effects of Rupture Complexity on Local Tsunami Inundation: Implications for Probabilistic Tsunami Hazard Assessment by Example, Journal of Geophysical Research: Solid Earth, 120(1), 488-502. https://doi.org/10.1002/2014JB011301

Mulia, I.E., Gusman, A.R., Satake, K., 2017. Optimal Design for Placements of Tsunami Observing Systems to Accurately Characterize the Inducing Earthquake. Journal of Geophysical Research Letters, 44(24), 106-12, 115. https://doi.org/10.1002/ 2017GL075791

National Oceanic and Atmospheric Administration (NOAA), n.d.. Deep-ocean Assessment and Reporting of Tsunamis. [Online] Available at: <https://nctr.pmel.noaa.gov/Dart/> [Accessed December 2019].

Okal, E.A., 2015. The Quest for Wisdom: Lessons from 17 Tsunamis, 2004-2014. Philosophical Transactions of the Royal Society A: Mathematical, Physical and Engineering Sciences, 373(2053). https://doi.org/10.1098/rsta.2014.0370

Okinawa Prefecture Civil Engineering Department, 2015.
Outsourced Setting of Okinawa Tsunami Inundation Assumptions. [Online] (Updated March 2015) Available at: $<$ https://www.pref.okinawa.jp/site/doboku/kaibo/h27tunami/d ocuments/gaiyoubann4-1.pdf $>$ [Accessed August 2019].

Omira, R., Baptista, M.A., Matias, L., Miranda, J.M., Catita, C., Carrilho, F., Toto, E., 2009. Design of a Sea-level Tsunami Detection Network for the Gulf of Cadiz. Natural Hazards and Earth System Sciences, 9(4), 1327-1338. https://doi.org/ 10.5194/nhess-9-1327-2009

Percival, D.B., Denbo, D.W., Eblé, M.C., Gica, E., Mofjeld, H.O., Spillane, M.C., Tang, L., Titov, V.V., 2011. Extraction of Tsunami Source Coefficients via Inversion of DART®buoy Data. Journal of Nat. Hazards Earth Syst. Sci, 58(1), 567-590. https://doi.org/10.1007/s11069-010-9688-1

Pugh, D., Woodworth, P., 2014. Sea-Level Science: Understanding Tides, Surges, Tsunamis and Mean Sea-Level Changes. Cambridge University Press, Cambridge

Rehman, K., Cho, Y.S., 2016. Building Damage Assessment Using Scenario Based Tsunami Numerical Analysis and Fragility Curves. Journal of Water, 8(3), 109. https://doi.org/10.3390/ w8030109

Schindele, F., Loevenbruck, A., Hebert, H., 2008. Strategy to Design the Sea-level Monitoring Networks for Small Tsunamigenic Oceanic Basins: the Western Mediterranean Case. Natural Hazards and Earth System Sciences, 8(5), 1019-1027. https://doi.org/10.5194/nhess-8-1019-2008

Titov, V.V., Gonzalez, F.I., Bernard, E.N., Eble, M.C., Mofjeld, H.O., Newman, J.C., Venturato, A.J., 2005. Real-time Tsunami Forecasting: Challenges and Solutions. Natatural Hazards, 35(1), 41-58. https://doi.org/10.1007/s11069-0042403-3

Wang, X., 2008. Numerical Modelling of Surface and Internal Waves over Shallow and Intermediate Water. ph.D. Dissertation, Cornell University, USA.

Wu, T.R., Chen, P.F., Tsai, W.T., Chen, G.Y., 2008. Numerical Study on Tsunamis Excited by 2006 Pingtung Earthquake Doublet. Terrestrial, Atmospheric and Oceanic Sciences, 19(6), 705-715. https://doi.org/10.3319/TAO.2008.19.6.705(PT)

Yoon, S.B., 2002, Propagation of Distant Tsunamis over Slowly Varying Topography. Journal of Geophysical Research: ceans, 107(C10), 3140. https://doi.org/10.1029/2001JC000791 